\title{
La política del desarrollo regional en Yucatán: descentralización administrativa y empresariado
}

\author{
Luis Alfonso Ramírez
}

La prolongada crisis de la agroindustria henequenera en Yucatán propició una profunda modificación de las estructuras económicas, de las vías de movilidad social y de la cultura de la sociedad regional en su conjunto. Esto repercutió con mayor fuerza en la ciudad capital y en la zona henequenera en torno a Mérida, que a lo largo del siglo Xx ha sido el centro urbano más grande e importante de la península de Yucatán. La economía de plantación henequenera generó una sociedad estructurada en torno a un eje de explotación agrícola que especializó durante muchos años a la planta industrial en la cordelería y la desfihración, $e$ hizo depender de ello, directa o indirectamente, a gran parte del empleo urbano. A partir de 1970 la dinámica urbana de la ciudad de Mérida comienza a alejarse de este patrón de crisis.

La ponencia se centra en los antecedentes y el contexto en que se produce el cambio urbano de una sociedad heredera de una cultura de plantación, analiza la búsqueda de alternativas de diversificación del empleo urbano a partir de una industria alejada del henequén, así como las tensiones y acercamientos entre el empresariado industrial privado y las políticas de desarrollo industrial entre 1970 y 1992, incluyendo a la industria maquiladora. Se pone especial énfasis en las estrategias políticas de gestión empresarial; por último, reflexiona sobre las perspectivas del empleo urbano a partir de las condiciones de industrialización de los años noventa.

\section{El contexto regional}

Durante la década de los setenta y hasta 1982, el sur y sureste de México adquirieron una creciente importancia dentro de los proyectos nacionales de desarrollo, debido al descubrimiento y confirmación de la existencia de las mayores reservas de hidrocarburos del país. Su explotación llevó en pocos años a una intensa inversión estatal, que en algunos casos modificó de manera radical los tradicionales horizontes socioeconómicos existentes en las distintas entidades, generando una serie de polos de desarrollo muy localizados, centrados en la extracción y transformación del petróleo y sus derivados.

La explotación petrolera cambió de manera sustancial la economía, las relaciones sociales y de poder de las localidades en la que se llevó a cabo, en muy poco tiempo y de manera radical. Es- 
to sucedió, por ejemplo, en Isla del Carmen, centro de operaciones de las plataformas petroleras de la sonda de Campeche, y en Coatzacoalcos y Minatitlán, ciudades organizadas en torno a los grandes complejos industriales dedicados a la transformación de hidrocarburos.

De manera secundaria, la explotación petrolera también influyó sobre los centros urbanos de mayor importancia de la zona, en especial Villahermosa pero también Campeche y Mérida, y al sureste en su conjunto, que se vio mejor comunicado y se integró con mayor fuerza a los mercados nacionales. Se experimentaron profundas modificaciones en las tendencias de los movimientos de población respecto a años anteriores, así como en los ritmos de crecimiento urbano. La región comenzó a adquirir una mayor importancia para el Estado, y se le otorgaron cuotas crecientes dentro de los presupuestos anuales destinados por la Federación. También se dieron pasos tendientes a dotar a sus centros urbanos de mejor infraestructura. Esto fue especialmente cierto durante los años de auge petrolero del sexenio de López Portillo, cuando se auguraba un crecimiento ininterrumpido a través del petróleo.

La ancestral vocación agrícola y pecuaria con la que durante muchos años se asoció al trópico húmedo y subhúmedo mexicano, empezó a modificarse. La crisis económica detuvo el acelerado crecimiento de la inversión petrolera, y muchos de los cambios previstos quedaron como pálidas sugerencias. Pero en muchas formas las transformaciones sufridas en esta década tuvieron un impacto social de mayor duración. Esto es especialmente cierto en tres campos. El primero es la creación de un mercado regional integrado, que se mueve a través de los principales centros urbanos del sureste y que se ha visto favorecido por el impulso a la infraestructura de comunicaciones y la red de caminos. El segundo es una nueva dinámica de población que ha modificado los flujos migratorios así como el tamaño y la composición demográfica, ${ }^{1}$ y el tercero es la interiorización y el manejo de nue-

1 Si nos concentramos en los tres estados de la península de Yucatán, Campeche y Quintana Roo, podremos ver que para 1980 Yucatán mantenía su preeminencia al concentrar $62 \%$ de la población total, es decir 1063733 habitantes sobre un total de 1710271 . Pese a ello, este porcentaje era $10 \%$ menor que en 1970 y $20 \%$ menor que en 1960 , señalando que en los últimos veinte años el dinamismo demográfico de los otros dos estados peninsulares ha sido mayor (Conapo, 1986; $X$ Censo General de Población y Vivienda; Unikel, Ruiz y Garza, 1976). 
vos mecanismos de gestión política con la burocracia y los aparatos del Estado, por parte de los sujetos sociales. Estos factores han generado una dinámica de cambio que afecta a la región en su conjunto.

Existen, por supuesto, profundas diferencias entre los distintos estados del sureste. En Tabasco el perfil señalado se delinea con mayor precisión. En Campeche la explotación petrolera reciente, orientada más a la extracción que a la transformación, ha reducido las repercusiones del petróleo en su economía. En los otros dos estados de la península, Yucatán y Quintana Roo, la influencia del auge petrolero ha sido periférica, introduciendo transformaciones más bien en los tres campos ya señalados. Al margen de la política petrolera, los estados peninsulares han recibido una renovada atención por parte del Estado, efectuándose en ellos proyectos de inversión tendientes a lograr cambios en las pautas de desarrollo regional. En el caso de Quintana Roo, los esfuerzos de la federación se han volcado en el fomento del polo turístico de Cancún, ${ }^{2}$ ciudad creada en 1976 y que para los años noventa alberga a más de 200000 habitantes.

En Yucatán, la presencia masiva de recursos del Estado ha seguido un derrotero distinto. Considerando la particular historia de la industria henequenera de la entidad, ${ }^{3}$ durante los años setenta y ochenta el mayor esfuerzo estatal en el campo se centró, más que en la inversión henequenera, en numerosos y en su mayor parte fallidos intentos de diversificación agrícola y pecuaria del campo, en los que se ha buscado, por distintas vías, hallar alternativas a la difícil vocación de sus suelos y su clima, enfrentándose a las limitaciones propias de la agricultura y ganadería de las zonas tropicales, así como al deterioro ecológico y a las condicionantes sociales propiciados por una agricultura de plantación en

2 El gobierno federal ha concentrado recursos en este punto del Caribe. Por ejemplo, en 1977 el financiamiento vía Fonatur a Yucatán fue sólo de 7 millones de pesos, una bicoca comparado con los 288 millones destinados a Cancún. Estas proporciones se mantuvieron. En 1984, de los más de 30000 millones de pesos otorgados por Fonatur en el país, sólo 115 se destinaron a Yucatán, y más de 3656 se manejaron en Cancún (INEGI, 1985).

${ }^{3}$ El henequén, planta tradicional del campo yucateco, sustentó una dinámica agrícola de plantación durante el porfiriato que se mantuvo durante la primera década revolucionaria. Hacia 1916 existían alrededor de 320000 ha sembradas de henequén y se exportaron más de 200000 ton de fibra, en especial al mercado norteamericano (Askinasy, 1936: 100; Betancourt, 1986: 54). 
decadencia. ${ }^{4}$ Ante este panorama el Estado ha intentado, en la última década, impulsar otros sectores de la economía y buscar apoyo en otros sujetos sociales, principalmente los empresariales.

\section{Los empresarios, el Estado y la modernización}

El estilo de desarrollo hacia el que se ha orientado la nación desde 1982 implica una decreciente inversión pública directa en empresas productivas, y una apertura política y de atracción del capital privado nacional y extranjero en las actividades económicas. Busca hacer participar a México con mayor fuerza en la división internacional del trabajo y tener acceso, a través de una industria de alta calidad, a los mercados extranjeros. Mediante la reconversión industrial se quiere crear una planta competitiva que pueda incrementar y diversificar las exportaciones del país.

Congruentes con esta tendencia general, los grandes proyectos de desarrollo en el sureste presentan, en la década de los noventa, una particularidad: se trata de fomentar, a mediano y largo plazos, actividades orientadas hacia el exterior y generadoras de divisas. La extracción petrolera de Campeche, el turismo en Quintana Roo, así como la combinación de parques industriales para maquiladoras y la creación de un puerto de altura que apoyará al turismo y a la exportación en Yucatán, son iniciativas tendientes a lograr este objetivo, de cara al futuro inmediato y otorgando cada vez menos peso al sector agropecuario.

La prioridad inmediata es atraer capital privado y generar productos exportables, más que empleo. Los flujos de capital no siempre se presentan positivos para el espacio en el que se generan. Por ejemplo, en el turismo de Quintana Roo y Yucatán la gran inversión extranjera sustrae una parte importante de los ingresos. En las maquiladoras sucede algo similar, y en el caso del petróleo es la administración federal la que se beneficia. El desarrollo que se propicia no genera una redistribución proporcional de los ingresos. Por supuesto, se genera cierto nivel de empleo y una demanda agregada de bienes y servicios de diversa índole, que dinamiza a otros sectores de la industria regional, particularmente a la de construcción y a la de bienes de consumo no duradero.

Las repercusiones que tiene este estilo de desarrollo no con-

4 En 19\%6, existían 157000 ha de henequén que produjeron 98350 ton de fibra. Siete años después, en 1983, la superficie se había reducido a 116666 ha y la producción a 63825 ton (Dirección de Economía Agrícola, SARH). 
tribuyen más que en una pequeña medida a solucionar los problemas regionales de empleo e ingresos, dado que sus demandas son de baja intensidad y corta duración, y sus cuadros de especialistas suelen ser cubiertos por personal foráneo. No parecen tampoco generar ritmos significativos de reinversión de capital en actividades productivas. Estos polos de inversión tienden a generar cambios acentuados en los espacios geográficos y económicos en los que se instalan, y su planificación rara vez considera de manera integral sus consecuencias, principalmente el impacto sobre la ecología, la inflación en la región circundante y el desequilibrio de la estructura sociopolítica local.

La inversión del Estado en Yucatán empezó a orientarse con mayor fuerza de la creación de infraestructura al financiamiento de actividades productivas hacia fines de los años cincuenta. La injerencia política lograda a través de la expropiación cardenista de los henequenales, ${ }^{5}$ se vio acompañada de la necesidad de una mayor inversión estatal conforme se acentuaba la crisis económica en esta actividad, 6 cuando el Estado se adueñó de la planta productiva cordelera, monopolizando una agroindustria de la cual el capital privado se retiraba ya.7

Durante los años sesenta y setenta el gasto estatal en Yucatán se orientó fundamentalmente al sector primario, en tanto que el capital privado empezaba a incursionar con timidez en nuevas actividades comerciales e industriales.

Si consideramos las relaciones sectoriales de Yucatán, podemos observar que las tendencias que se han mantenido homogéneas en la última década son el predominio del comercio, los servicios y el turismo, seguidos, de manera secundaria, por el desarrollo de la industria, con un sector agropecuario estancado y una inversión estatal que, después de algunos años de incremento sustancial, tiende a replegar su participación directa en la inversión productiva, fomentando obras de infraestructura y propiciando la inversión de capital privado. Aunque gran parte del dinamismo de las actividades económicas privadas se explica por el

${ }^{5}$ En 1927, la superficie sembrada había bajado a 234000 ha y en 1934 a 160000 ha que fueron las afectadas por la reforma agraria cardenista. Para un análisis estadístico más amplio sobre este periodo, véase Aznar Mendoza (1974: 727-787). El estado en que se encontraba toda la zona henequenera durante la implantación de la reforma agraria puede leerse en "El ejido henequenero de Yucatán”, 1941.

6 En 1983, el henequén apenas aportaba $18.3 \%$ del valor de la producción agrícola, cuando en 1976 significaba más de la mitad (Villanueva Mukul, 1990: 47).

7 "Cordemex", la paraestatal que controla al mercado cordelero y gran parte de la desfibración desde 1964, fue puesta en venta en mayo de 1991 al sector privado, dividida en cuatro empresas. 
dinero del gobierno, ${ }^{8}$ algunas grandes empresas, particularmente las relacionadas con actividades comerciales y con la producción de bienes de consumo no duradero, van adquiriendo una dinámica propia, integrándose a los mercados regionales. De esta manera, la doble dependencia de Yucatán, del henequén y la inversión y gasto directos del Estado, empieza a modificarse en la década de los noventa. ${ }^{9}$

Si en algunos puntos de la economía (por ejemplo, el sector agropecuario) la dependencia se mantiene, en otros, las políticas puestas en marcha a partir de 1982, orientadas a ofrecer una mayor participación en la vida económica y política del país al sector empresarial, han provocado cambios regionales. Los nuevos espacios de acción han multiplicado la capacidad y las tendencias monopólicas del capital privado, permitiéndole un crecimiento sostenido en función de su habilidad para expandir sus mercados hacia todo el sureste y acomodarse a los cambios en la demanda, buscando además nuevas formas de asociación de capital para ser más competitivos, y en algunos casos exportar a los mercados tanto del sureste norteamericano como del Caribe. La relación actual entre el Estado y la iniciativa privada de la región, en una estructura económica más diversificada, que se ha alejado del monocultivo, tiende hacia la simbiosis más que a la dependencia o el enfrentamiento.

Hay que resaltar un cambio crucial tanto en lo económico como en lo político. Se trata de la mayor importancia que han adquirido los ingresos manejados e invertidos por el gobierno del estado, frente a los que se controlan directamente desde el Distrito Federal.10 Esto empieza a suceder desde 1982, y es resultado de las políticas de descentralización administrativa. El incremento

8 Hasta principios de los años ochenta la inversión del Estado constituyó uno de los motores de la economía. Entre 1971 y 1975 se triplicó a precios corrientes y se duplicó a precios constantes. Entre 1980 y 1984 la inversión se volvió a triplicar a precios corrientes (Secretaría de Programación y Presupuesto, 1977-1987).

${ }^{9}$ La tesis de la "doble dependencia" en Yucatán se discute por distintos autores desde los años setenta. Véanse por ejemplo, los trabajos de Iván Menéndez $(1977,1978,1979$ y 1982). Otros autores la aceptan de manera implícita, como por ejemplo Argáez y Montañez (1975). Recientemente existen enfoques que sustituyen el concepto estático de dependencia por uno más dinámico de interrelación entre sistemas complejos, por ejemplo el de Vera Pren (1990).

10 Desde el último año del sexenio de López Portillo se empezó a dejar en manos de los gobiernos estatales un porcentaje importante de los recursos financieros; este aumentó con los programas de descentralización administrativa impulsados por De la Madrid. Así, en 1983 los ingresos del gobierno del estado superaron por primera vez en muchos años la inversión pública federal directa, volviendo a bajar ligeramente en 1984, siendo casi idénticos en 1985 y superándola de nuevo en 1986. 
sustancial de los recursos manejados por el gobierno local, frente a los que invierten las dependencias federales ha tenido importantes repercusiones. La asociación entre empresarios locales y funcionarios estatales ha sido más íntima. La descentralización y una mayor autonomía de las gubernaturas en algunos niveles del proceso de toma de decisiones del uso de recursos ha despertado un creciente interés empresarial por intervenir en el aparato político, llegando incluso a la participación directa de connotados empresarios dentro de las principales carteras encargadas del manejo económico, ${ }^{11}$ ocupadas, en los tres distintos regímenes que se han sucedido desde 1984, por algunos de los más importantes empresarios de la región.

El contacto de los empresarios locales con la inversión pública ha sido también mayor durante estos últimos ocho años. Las alianzas empresariales con los distintos grupos políticos locales han sido cruciales como mecanismos de gestión informal para acceder a concesiones de obras, de abastecimiento, servicios profesionales y créditos preferenciales. En este sentido el "instinto político" de los empresarios locales se ha vuelto más agudo, enmarcado al mismo tiempo en la mayor participación partidista y pública fomentada o permitida por el Estado en el ámbito nacional. El repunte de algunos grupos de capital privado en estos últimos años, e incluso el auge de empresas específicas, tienen mucho que ver con su mayor participación en el destino de las finanzas públicas (Ramírez Carrillo, 1991a: 541-568).

Mencionaremos dos ejemplos en los que estos mecanismos de gestión empresarial revelan la influencia de los intereses y del poder locales en el proceso de descentralización política y administrativa, dentro del carácter aún limitado de este último. El primero es la industria maquiladora, ${ }^{12}$ particularmente interesante, pues en ella participan tanto las iniciativas del Estado como el capital privado local y la inversión extranjera. Fomentar las maquiladoras en Yucatán fue una sugerencia que en realidad hizo el gobierno federal a partir de 1984 . Se esperaba que fuera alternativa generadora de empleo para una población campesina desocupada en las plantaciones henequeneras. La puesta en marcha del programa quedó en manos del gobierno del estado, que a su vez se

11 El proceso de vinculación de algunos de los más importantes empresarios yucatecos al poder político y su ascenso social hasta controlar grandes corporativos comerciales e industriales en Yucatán es analizado por Luis Alfonso Ramírez (1991a, 1991b y 1989).

12 Para una descripción de las maquiladoras instaladas en Yucatán hasta 1989 véase Mendoza et al. (1990). 
vinculó a un pequeño grupo de empresarios; -funcionarios e inversionistas actuaron de manera conjunta-e influyó para que este programa tuviera prioridad frente a otras alternativas de promoción del desarrollo.

Así, los empresarios locales, con recursos especiales del Estado, impulsaron dos parques industriales para la instalación de maquiladoras y despachos de asesoría profesional; el gobierno otorgó un apoyo general mediante la dotación de infraestructura y labores de promoción,13 y los capitales foráneos han efectuado la inversión directa. Mediante este impulso, desde 1984 el gobierno estatal emprendió una agresiva campaña de promoción en Norteamérica, Europa y Asia, vendiendo en especial la "privilegiada" posición de Yucatán respecto al mercado norteamericano (a 500 millas marítimas de los estados del sureste de Estados Unidos), prometiendo apoyo gubernamental en infraestructura y exenciones fiscales, subrayando la desorganización y falta de sindicalización de la fuerza de trabajo y su menor costo frente a los estados maquiladores del norte de la República.

Como consecuencia, en 1986 ya se encontraban instaladas cuatro industrias; dos en operación y otras dos que comenzaron a operar en 1987. A principios de 1988 estaban ya en distintos grados de instalación u operación otras ocho (Beatriz Castilla, 1989: 30). Para 1992, más de veinte maquiladoras operaban o habían iniciado acciones para instalarse en Yucatán. La cifra es pequeña si la comparamos con las que se encuentran en los estados fronterizos del norte, y su repercusión en la estructura global no ha sido hasta ahora de mucha importancia.

Las maquiladoras no se han comportado de acuerdo con las expectativas locales ni centrales. Hasta 1990, apenas la mitad de las instaladas se asentaban en los parques industriales administrados por empresarios locales. Esto, aunado al lento ritmo de su llegada, ha hecho que las ganancias en este negocio sean muy inferiores a las previstas. Por otra parte, en cuanto a la generación de empleos, ${ }^{14}$ ni la cantidad de plazas ni la población impactada ha sido la programada, pues la mayor parte del empleo generado es desempeñado por mujeres. En diciembre de 1988 había 1168 obreras contra apenas 140 hombres laborando, además de que se trata de mujeres urbanas de la ciudad de Mérida. Esta situación

${ }^{13}$ Entre 1985 y 1987 el gobierno estatal destinó más de 1000 millones de pesos anuales a la promoción internacional para la instalación de maquiladoras.

14 La estructura del empleo en Yucatán se orienta fundamentalmente hacia el sector de comercio y servicios. La planta industrial no ocupa a más de $30 \%$ de la población con empleo formal no agrícola, que a su vez, apenas supera a 50\% de la PEA. 
no ha paliado el intenso desempleo masculino existente en la zona henequenera que circunda el área metropolitana de Mérida, y debido a la alta circulación y poca duración de las obreras en las plantas, las maquiladoras tampoco solucionan la creciente falta de plazas de trabajo estables para la población asentada en las colonias marginadas de la ciudad. 15

Un segundo ejemplo de cómo los intereses y la gestión política del empresariado impactan el desarrollo regional, lo constituye una enorme obra pública: la construcción y puesta en operación de un puerto de altura en la costa, a $33 \mathrm{~km}$ de la ciudad de Mérida. Este puerto, consistente en una isla de concreto unida a tierra firme por un viaducto de $6.5 \mathrm{~km}$ de longitud, constituyó una de las obras de ingeniería náutica más importantes realizadas en México en la década pasada. Su construcción se realizó entre 1985 y 1989 y se invirtieron en ella alrededor de 110000 millones de pesos. Es decir, que gran parte del gasto de la federación destinado a Yucatán durante este periodo, fue para el puerto, descuidando otro tipo de actividades prioritarias, tanto de carácter productivo como de generación de infraestructura.

Si bien en la elección de erigir una obra de esta magnitud influyeron numerosos factores, la opinión y estrategias de los empresarios locales a través del gobierno del estado, fueron de la mayor importancia. Tres poderosos grupos empresariales vinculados a los mercados internacionales y al sector exportador generaron argumentos a favor. Uno de ellos esperando incrementar su plataforma de exportación de cemento a Estados Unidos a un millón de toneladas anuales por vía marítima, otro con la esperanza de abaratar los costos de importación de insumos para sus numerosas fábricas de alimentos balanceados en todo el sureste, y un tercero queriendo incluir a Yucatán en la lista de los cruceros turísticos del Caribe. A esto se sumaron los intereses de una gran empresa local cercana al gobierno estatal, que logró el contrato de la obra, y en consecuencia, hubo puerto de altura. Para percatarnos de cómo una obra de esta naturaleza puede influir sobre el proceso de crecimiento económico regional, basta señalar que lo gastado en ella fue muy superior a la suma destinada al sector agrícola, pecuario, pesquero e incluso al equipamiento de infraestructura urbana en todo el periodo. En tres años de operación, el puerto de altura no ha representado ventajas excepto para los grupos empresariales inicialmente interesados.

15 Diversas formas de empleo informal y desempleo urbano, así como actividades de subsistencia rurales, son la realidad de la población yucateca (Luis Alfonso Ramírez, 1990: 91-130). Para un detallado análisis de la evolución y composición de la PEA en Yucatán consultar a Castilla (1991: 23-52 y 177-206). 
Las nuevas relaciones de apertura política y la inclusión de los empresarios y el capital privado en los grandes proyectos nacionales, obedecen a una dinámica social más amplia, que en el sexenio salmista ha sido denominada modernización y que se orienta a redefinir en todos los ámbitos de la cultura, la política y la economía, las relaciones entre el poder de Estado y la sociedad civil. Los empresarios se apuntan como uno de los grupos privilegiados de la sociedad civil en este proceso de cambio, al coincidir con mayor fuerza sus intereses particulares con el proyecto de nación deseado y programado desde el poder político.

De los principales grupos que dirigen las empresas de mayor tamaño de Yucatán en 1993, 42 de ellos son propiedad del capital privado regional, o bien los capitalistas yucatecos tienen acciones mayoritarias. De estos grupos empresariales, 23 dedicados a la ganadería, la construcción, el turismo, el comercio, la distribución automotriz y las comunicaciones, son propiedad o están controlados por familias de apellido hispano originadas en la clase media local, que en el curso de una a tres generaciones ascendieron socialmente.

Doce grupos empresariales están en manos de familias de origen libanés dedicadas a la industria, el comercio y la construcción, que iniciaron su ascenso social desde posiciones de miseria, a partir de principios de siglo; cinco, relacionados con el turismo, la industria y la distribución automotriz, corresponden a familias que empezaron a destacar en el porfiriato, vinculadas desde entonces al comercio y la industria, más que a las haciendas. Finalmente, sólo uno de los grupos empresariales de importancia es propiedad de una familia de apellido maya y origen humilde.

De las empresas restantes, 19 son las representaciones locales de grandes grupos y monopolios nacionales. Dominan las ramas dedicadas a la avicultura, la panificación, la producción de bebidas, derivados plásticos, cemento, construcción, alimentos y bolsa. Las grandes empresas nacionales presentes en Yucatán, con importantes inversiones de capital, se ubican principalmente en la industria y en menor medida en el comercio. Finalmente tenemos 18 grandes empresas en manos del gobierno federal, dedicadas a proveer servicios financieros, comunicaciones y energéticos; una gran empresa cordelera que entre 1990 y 1993 pasó de manos del gobierno estatal a las de cuatro consorcios privados (Cordemex) y otra de capital mixto dedicada a la producción de alimentos balanceados.

Las características actuales de Yucatán apuntan hacia una estructura productiva diversificada, con presencia importante de inversión y empresas del Estado, pese al proceso de privatización que se empezó a impulsar desde 1982. De igual manera, hay una 
profunda integración a los mercados nacionales e internacionales, con presencia de muchos de los monopolios más importantes del país. Los empresarios locales controlan aún, más de la mitad de los consorcios mayores. Se caracterizan por ser una élite heterogénea de negocios, producto de más de medio siglo de movilidad social, que desde fines de los años setenta ha presentado la tendencia a reunir sus empresas familiares en grupos corporativos, en los que aún se subordina la administración profesional a los imperativos de la dinámica familiar.

Si bien la decadencia de la economía de plantación es evidente y su impacto sobre el empleo rural nunca ha podido ser solucionado por el Estado, los cambios propiciados en la región por la descentralización administrativa -que no política- han creado otros espacios de especialización económica y ampliado la presencia de los grupos empresariales en el poder. Los recursos de todo tipo son ahora mucho mayores que en el pasado, y si bien hay puntos de concentración monopolizados por el Estado, la iniciativa privada ha podido hacerse de enormes capitales al participar de una manera privilegiada en el proceso regional de desarrollo, en especial durante los últimos veinte años.

La burguesía local enriquecida aceleradamente en este último periodo, controla recursos mayores, pero mucho más difusos que en el pasado debido a la descentralización. En Yucatán podemos observar a lo largo del siglo, cómo se ha dado el paso de una élite monopólica o concentrada, con un carácter uniforme y que controlaba recursos económicos y políticos, a otra abstracta, abierta en su reclutamiento, que concentra grandes recursos de capital distribuidos a lo largo de una economía compleja. Esta élite, al monopolizar sus propios sectores de acción, puede llegar a tener una gran influencia dentro de ellos, pero interactúa con otras fracciones y con los monopolios nacionales, y depende, en partes de su proceso de toma de decisiones, de las políticas del Estado mexicano.

Se suele señalar que los grupos empresariales de mayor importancia y con más definición y fuerza política, son los del norte y el centro del país, ubicados espacialmente en Monterrey y la ciudad de México. Ante esta imagen los empresarios del sur y el sureste aparecen como de escaso tamaño y poca importancia. Aunque en el concierto de la política nacional esto puede ser verdad, en términos regionales su importancia es grande y las inversiones que se llevan a cabo en la actualidad, así como el proceso de cambio político y social que se está gestando en distintas partes de México, es incomprensible sin un análisis de su participación, así como el de los intereses privados y las relaciones de po- 
der que entran en juego en el proceso de toma de decisiones de la acción gubernamental.

El empresariado del sureste es más semejante al del centro de México que al del norte. La independencia empresarial, la actitud crítica frente al Estado y el alejamiento del aparato administrativo, son mayores entre los empresarios del norte, más vinculados a la economía norteamericana, que entre aquellos que tienen como centro al valle de México, cercanos y con vínculos directos en la administración pública y el gobierno. El empresario yucateco, como el del valle de México, se encuentra vinculado con mayor fuerza al aparato político y administrativo que el de otras regiones del país. Aunque en su lucha por el control de los nuevos recursos liberados por la descentralización incrementa su presencia política y se puede expresar de manera contestataria, por lo general sus intereses y su manera de operar lo obligan a actuar con prudencia en sus actos de crítica al poder. La red de relaciones que comparte con los miembros de la clase política local lo motiva más a pactar que a pelear, y estos pactos ocultos, que bien pueden ser comprendidos como estrategias informales de gestión, van configurando las vías de lo que retóricamente se denomina "modernización" en el sureste mexicano.

\section{Bibliografía}

Argáez, I. y Carlos Montañez (1975), Yucatán. Las condiciones del desarrollo de la agricultura de subsistencia, Mérida, Universidad Autónoma de Yucatán.

Askinasy, Siegfried (1936), El problema agrario de Yucatán, México, Ed. Botas.

Aznar Mendoza, Enrique (1977), "La industria henequenera desde 1919 hasta nuestros días", en Echanove Trujillo/Gobierno del Estado de Yucatán (comps.), Enciclopedia Yucatanense, t. III, pp. 727-787.

Betancourt, Antonio (1986), Revoluciones y crisis en la economía de Yucatán, Mérida, Maldonado Editores.

Castilla, Beatriz (1989), "La industria maquiladora en Yucatán: Un nuevo modelo de desarrollo industrial", en El Cotidiano, año 6, núm. 31, pp. 26-32.

- (1991), La ocupación en Yucatán, Mérida, Universidad Autónoma de Yucatán.

Consejo Nacional de Población (1986), Diagnóstico de la distribución de la población en México, México, Conapo.

Gobierno del Estado de Yucatán (1941), El ejido henequenero de Yucatán, Mérida.

INEGI (1981), $X$ Censo General de Población y Vivienda, México.

(1986), Anuario de estadísticas básicas del Estado de Yucatán, México. 
- (1991), XI Censo General de Población y Vivienda, México.

Mendoza T. et al. (1990), Presencia y tendencia de la industria maquiladora en Yucatón, Mérida, Universidad Autónoma de Yucatán.

Menéndez, Iván (1977), "El estado y la zona henequenera de Yucatán, 1970-1976", en Comercio Exterior, vol. 27, núm. 12, pp. 1510-1516.

(1979), "Yucatán: la doble dependencia", en Comercio Exterior, vol. 28, núm. 8, pp. 960-968.

(1979), "Alternativas del desarrollo yucateco", en Revista de México Agrario, año xII, núm. I, México.

(1982), Lucha social y sistema político en Yucatán, México, Grijalbo.

Ramírez Carrillo, Luis A. (1989), "Género, parentesco y movilidad social”, Informe de Investigación, México, PIEM/El Colegio de México.

- (1991a), "Elites empresariales. Parentesco, coaliciones y empresarios en México: El caso de Yucatán”, tesis doctoral CES/EI Colegio de México.

(1991b), "Stratification, social mobility and kinship: entrepreneurs of lebanese origin in Yucatan", ponencia ILAs/Universidad de Texas en Austin.

(s/f), "Población y desarrollo en Yucatán y Mérida", Informe de Investigación, El Colegio de México/Universidad Autónoma de Yucatán.

Secretaría de Programación y Presupuesto (1977-1987), "Informes Económicos del estado de Yucatán", Mérida, Delegación regional.

Unikel, Luis, Crescencio Ruiz y Gustavo Garza (1976), El desarrollo urbano de México: diagnóstico e implicaciones futuras, México, El Colegio de México.

Vera Pren, Jorge Tomás (1990), "Las transformaciones de la estructura socioeconómica de Yucatán en el contexto del desarrollo capitalista del sureste a partir de la posguerra”, en Othón Baños (comp.), Sociedad, estructura agraria y estado de Yucatán, Mérida, Universidad Autónoma de Yucatán, pp. 433-477.

Villanueva Mukul, Eric (1990), "El subsistema henequenero y su relación con la economía regional", en Eric Villanueva et al. (coord.), El henequén en Yucatán: industria, mercado y campesinos, Mérida, Maldonado ed., pp. 11-68. 
